\title{
Development and Measurement of Learners' Satisfaction Index Model for Cyber Education
}

\author{
Chang-Su Kim, Hoe-Kyung Jung, Member, KIMICS
}

\begin{abstract}
Cyber education has been predicted that it would become the primary education system of 21 st century as a way of education focusing on consumers, with the aspect that it seems to be able to satisfy the demand about reeducation and lifelong education as the acceleration of fast knowledge accumulation throughout every field of society in the digital era. However, cyber education system has a lot of problems which are for that it lacks of human resources for effective interaction, and it can be disadvantageous to certain type of students with a class environment concentrated on reading and writing and with foundation on computer technology.

Therefore, in this thesis, We intended to analyze factors influencing satisfaction of people studying in a situation that cyber education has been required to be a mainstream system of education in the midst of trend of changing paradigm of college education recently, and to suggest some possible solutions for cyber education at university.
\end{abstract}

Index Terms - Cyber Education, Learner's Satisfaction, Satisfaction Model, Satisfaction

\section{INTRODUCTION}

As the society changes to information-oriented society, rapid increase of information and knowledge and the development of information and communications technology are provoking a change in the educational environment. Especially, development of technology of the info-communication and multimedia has brought form of cyber education using internet, deviating from form of education inside class with professors.

Cyber education has been predicted that it would become the primary education system of 21 st century as a way of education focusing on consumers, with the aspect that it seems to be able to satisfy the demand about reeducation and lifelong education as the acceleration of fast knowledge accumulation throughout every field of society in the digital era[1]. However, cyber education system has a lot of problems which are considerate in the lacks of human resources for effective interaction, and it can be disadvantageous to certain type of students with a

Manuscript received May 24, 2010; revised May 27, 2010; accepted June 1, 2010.

Chang-Su Kim is with the Department of Internet, Chungwoon University, Hongseong, 350-701, Korea (Email: ddoja@ mail.chungwoon.ac.kr)

Hoe-Kyung Jung(Corresponding Author) is with the Department of Computer Engineering, PaiChai University, Daejeon, 302-735, Korea (Email: hkjung@mail.pcu.ac.kr) class environment concentrated on reading and writing and with foundation on computer technology.

Therefore, in this thesis, I intended to analyze factors influencing satisfaction of people studying in a situation that cyber education has been required to be a mainstream system of education in the midst of trend of changing paradigm of college education recently, and to suggest some possible solutions for cyber education at university.

\section{MODEL FOR ESTIMATING SATISFACTION OF LEARNERS}

\subsection{Research model}

Referred NCSI research model[2] and informationsystem users satisfaction index model[3,4,5,6,7,8], we developed a research model as in Fig. 1, and with this model, we conducted confirmative factor analysis about relation of learners' satisfaction and loyalty in cyber education.

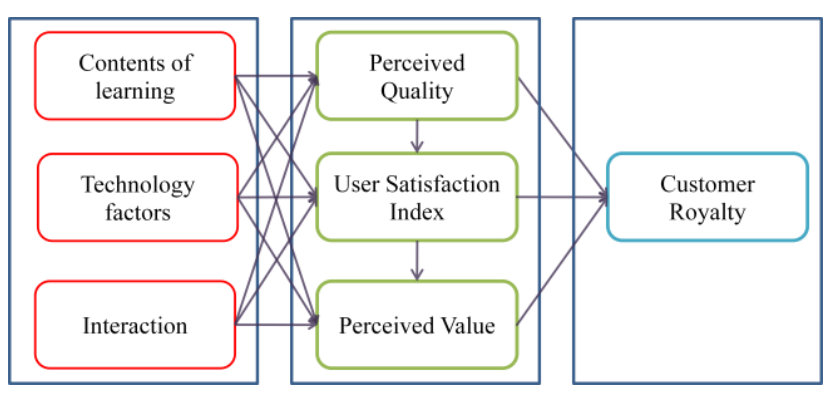

Fig. 1. Research model

About satisfaction of learners, research work was composed of contents of learning, factors from technology, and interaction. In the part of contents of learning, there are seven aspects: utility, properness, credibility, diversity, relation, structure, and whether it is easy to be understood.

Factors from technology are composed of four things: convenience for use and approach, speed of response and outer design, and interaction is made up of three parts: level of interaction, promptness, and identification service. Also we organized general satisfaction of using, recognized value, loyalty of learning, and recognized utility. 


\section{PLANNING FOR RESEARCH AND METHODOLOGY}

\subsection{Survey object and analysis method}

For learners' satisfaction survey for cyber education, questionnaire survey method for users who have experience in university cyber education was selected. Survey period was from December 1, 2009 to December 10 , and responded questionnaires of 380 cases were used as analysis data.

As analysis tool to analyze data for user satisfaction survey for information service, SPSSWIN16 version and Excel 2007 was used to derive calculation formula.

\subsection{Statistical characteristics of sample}

We analyzed statistical characteristics of a sample used in this thesis, classifying into sex, grade, college, experience of cyber classes.

In sex part, female comprises $45.5 \%$ and male does $54.5 \%$. In the 'grade' part, freshmen form $56.8 \%$, sophomore form $9.5 \%$, junior form $27.1 \%$, and senior $6.6 \%$, which indicate that from freshmen, and sophomore, junior, and then senior in order of majority. In 'college' part, colleges of science and engineering form $24.5 \%$, colleges of arts and broadcasting form $59.7 \%$, and colleges of hotel management form $4.5 \%$, and college of humanities and social sciences form 11.3\%: colleges of arts and broadcasting hold a majority among several colleges. In the part of experience for cyber learning, people who experienced held $46.3 \%$, and people who have never learned online held $52.4 \%$.

\subsection{Form of using cyber education of sample group}

We analyzed forms of using cyber education through figuring number of logging in, learning time, number of using bulletin boards, and participation of discussion and learning. For the number of logging into the service, people who logged in less than 20 times held $45.3 \%$, and people logged in more than 20 and less than 40 times held $42.6 \%$, and people logged in more than 40 and less than 60 times held $8.9 \%$, and for the last, people who did more than 60 times held $3.2 \%$. For learning time, people who studied more than 10 hours but less than 30 hours were $57.5 \%$, holding a majority, and people who did less than 10 hours held $23.7 \%$, and people who did more than 30 but less than 50 hours held $13.9 \%$, and people who did more than 50 hours held $4.5 \%$.

For the number of using bulletin boards, students who used less than 2 times were $70.5 \%$, and who used more than 2 but less than 5 times were $21.6 \%$, and who used more than 5 but less than 10 times were $4.7 \%$, and who used more than 10 times were $3.2 \%$ in the end. For the number of participation of the discussion board, students who used less than two times were $83.4 \%$, who used more than 2 but less than 5 times were $9.2 \%$, and who used more than 5 but less than 10 were $4.7 \%$, and more than 10 times held $2.6 \%$.
The actual participation rate of learning was: more than $75 \%-42.6 \%, 50 \% \sim 70 \%-32.9 \%, 25 \sim 50 \%-13.2 \%$, and less than $25 \%-11.3 \%$, in order of high percentage.

\section{RESULT FROM ANALYZING LEARNERS' SATISFACTION INDEX}

\subsection{Methods of measurement}

In this thesis, to measure satisfaction index about each component of category items, We converted Fornell formula which was originally based on out of 10 points, to out of 5 points for perfect score, so that We could evaluate the index using regression coefficient values from analysis of relationship of dependent variables and independent variables about each item.

\subsection{Calculation methodology}

We calculated integrated satisfaction index through results of first, value of total of satisfaction number of each component of classification multiple regression coefficient values, and second, a result that We calculated average after We added all general users satisfaction which was directly measured. A formula for calculating users satisfaction index is same as formula (1)

$$
\begin{aligned}
& T=0.7 \times\left(\sum_{i=1}^{n} C_{i} \times W_{i}\right)+0.3 \times S \\
& T=\text { Satisfaction } \quad C_{i}=\text { Category satisfaction } \\
& W_{i}=\text { Category weight } \quad n=\text { Category number } \\
& S=\text { General users satisfaction }
\end{aligned}
$$

Satisfaction index for each category component was calculated with formula (2), as a satisfaction index of contents of learning, factors from technology, and interaction, which influence the integrated satisfaction index on the whole.

$$
\begin{aligned}
C_{i} & =\frac{\left(\sum_{i=1}^{n} D_{i} \times W_{i}\right)}{4} \times 100 \\
C_{i} & =\text { Category satisfaction } D_{i}=\text { level satisfaction } \\
W_{i} & =\text { level weight } \quad n=\text { level number }
\end{aligned}
$$

Satisfaction index for each level is the index about levels which comprise contents of learning, factors from technology, and interaction. The formula for calculating this is the same with formula (3).

$$
\begin{aligned}
D_{i} & =\frac{\left(\sum_{i=1}^{n} I_{i} \times W_{i}\right)}{4} \times 100 \\
D_{i} & =\text { level satisfaction } I_{i}=5-\text { liketr average value } \\
W_{i} & =\text { item weight } n=\text { item number }
\end{aligned}
$$




\subsection{Measurement of satisfaction index}

4.3.1 Satisfaction index for each category component

Learners' satisfaction index of cyber education was calculated through three satisfaction indexes for each component, and the value which was applied with additional weights on those indexes, and general users' satisfaction. As we can see in the Fig. 2, the integrated satisfaction index was calculated as 87.6. Satisfaction for each component was calculated as: contents of learning 89.7, factors from technology 87.6, and interaction 77.9.

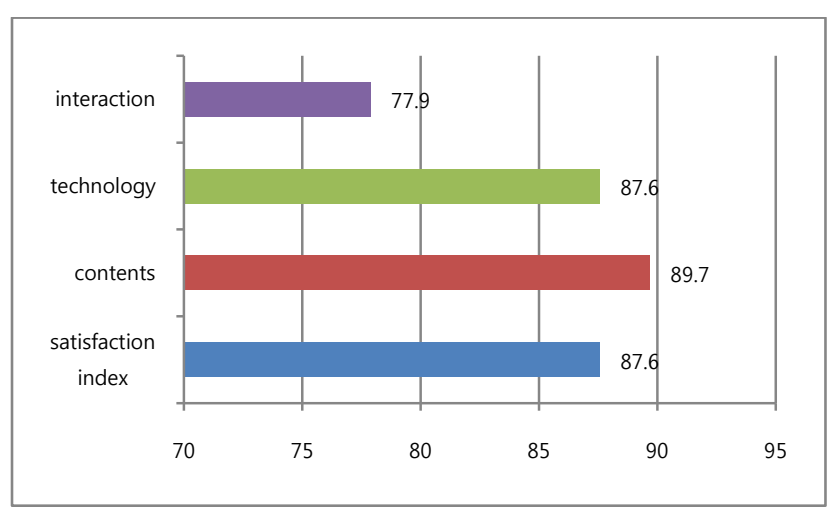

Fig. 2. Satisfaction index for each category component

\subsubsection{Satisfaction for each level}

(1) Satisfaction for contents of learning

Satisfaction about contents is composed of levels of utility, properness, credibility, diversity, relation, structure, and whether it is easy to be understood. The index result is: credibility -92.2 , relativity -91.0 , whether it is easy to be understood -89.6 , utility -89.4 , diversity -89.3 , and appropriacy -86.7 , in order from the highest to lower. Learners of cyber education indicated the lowest satisfaction about level of difficulty and the workload of learning contents.

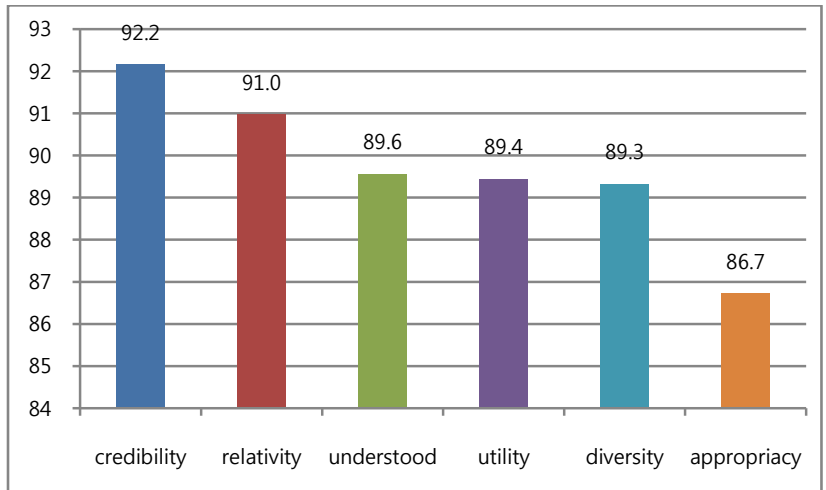

Fig. 3. Satisfaction for contents of learning

(2) Satisfaction for technology factors

Technology factors are convenience for use and approach, speed of response, outer design, and interaction. Satisfaction for these factors indicates that convenience for use was the highest with 93.5 and interaction was the lowest with 77.1. For the rest, layout design was 91.3, convenience for approach was 87.6, and the speed of response was 86.4 in order of highest result.

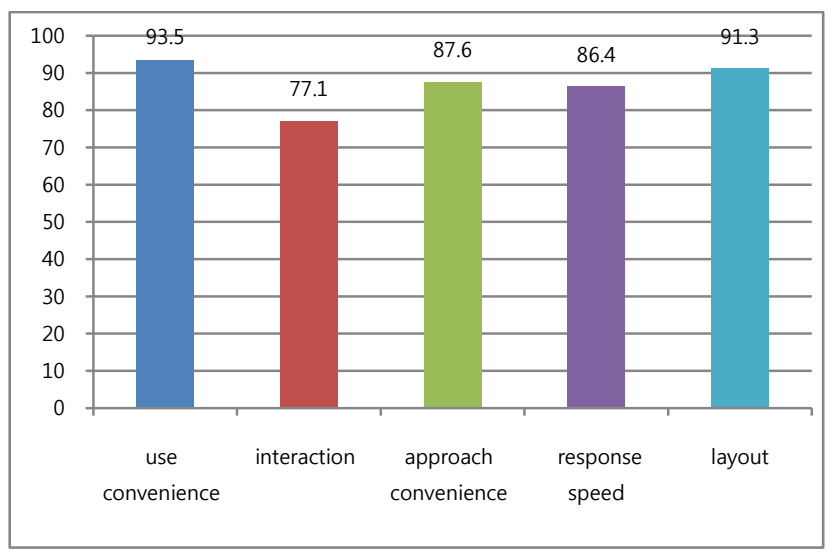

Fig. 4. Satisfaction for technology factors

(3) Satisfaction for Interaction

It is classified with credibility, promptness, and identification service, and the result was: promptness was the highest with 82.5 , and credibility was the lowest with 73.9. Satisfaction for sympathy service was 76.8

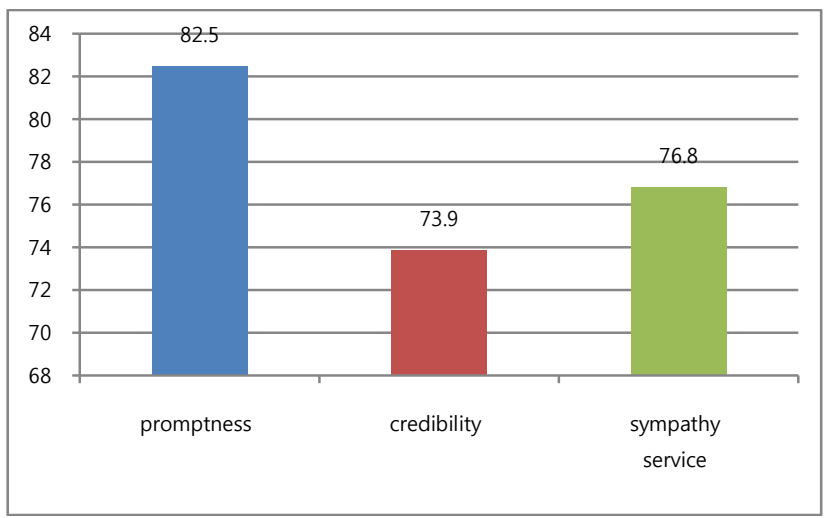

Fig. 5. Satisfaction for interaction

\subsubsection{Satisfaction for each user group}

The integrated satisfaction index for each user group was analyzed with distinction per each sex, grade, and college. For the sex part, male (86.7) was less higher than female (82.7), and for each level component, both indicated the same order in numbers: contents of learning, technology factors, and interaction.

For each grade, satisfaction of junior was highest: freshmen -79.0 , sophomore -76.4 , junior -85.1 , and senior -82.2 . From students of all grades, satisfaction for technology factors was the highest and for contents of learning was the lowest. For each college, the result was: college of humanities and social sciences (87.3), college of science and engineering (83.1), college of arts and broadcasting (77.9), and college of hotel management (77.1). 


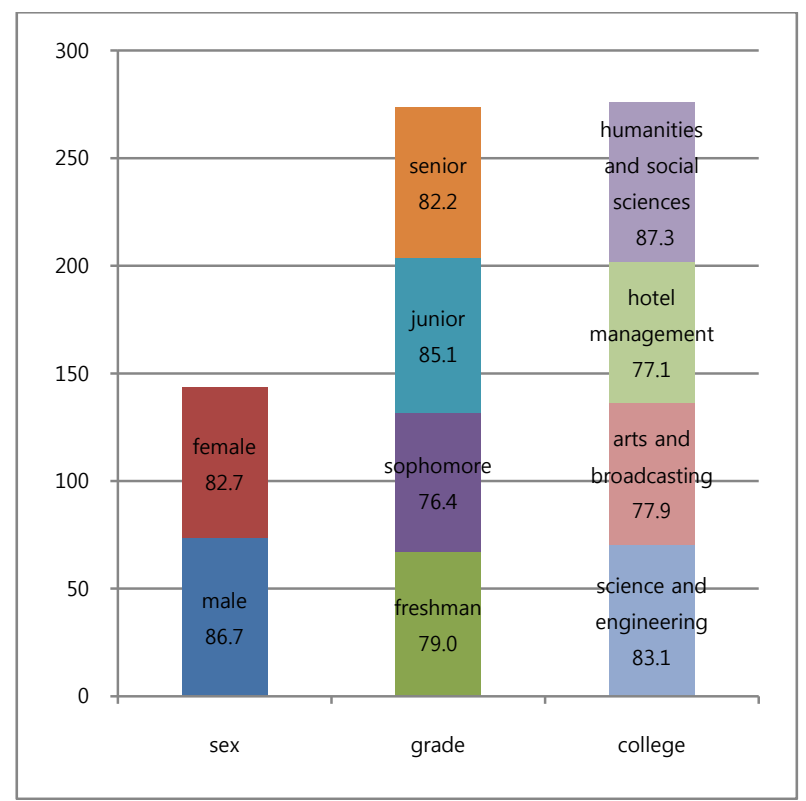

Fig. 6. Satisfaction for each user group

\subsection{Verification}

Then, to analyze relationship among components, We conducted confirmatory factor analysis, and evaluated suitability of the model. In this process, We used chi-square, GFI(Goodness of Fit Index), RMR(Root Mean square Residual), CFI(Comparative Fit Index), IFI(Incremental Fit Index) value. Furthermore, We repeated removing SMC(Squared Multiple Correlation) values to produce high suitability of the material.

The usual standard for suitability to choose a model is more than 0.9 of GFI, CFI, IFI value, and less than 0.05 of RMR value, so this material is enough to be accepted with great suitability. TABLE I is the result of factor analysis.

TABLE I

\section{RESULT OF CONFIRMATORY FACTOR ANALYSIS}

\begin{tabular}{|c|c|c|c|c|c|c|c|c|}
\hline \multicolumn{2}{|c|}{ scale } & $\begin{array}{c}\text { Level } \\
\text { number }\end{array}$ & $x^{2}$ & $\mathrm{p}$ & GFI & RMR & CFI & IFI \\
\hline \multirow{2}{*}{$\begin{array}{c}\text { Contents of } \\
\text { learning }\end{array}$} & early & 7 & 53.247 & .000 & .892 & .162 & .804 & .923 \\
\cline { 2 - 9 } & final & 5 & 1.952 & .328 & .932 & .042 & .957 & .968 \\
\hline \multirow{2}{*}{$\begin{array}{c}\text { Technology } \\
\text { factors }\end{array}$} & early & 5 & 121.42 & .000 & .768 & .072 & .916 & .893 \\
\cline { 2 - 9 } & final & 4 & 3.051 & .513 & .908 & .015 & .982 & 1.00 \\
\hline \multirow{2}{*}{\begin{tabular}{c} 
interaction \\
\cline { 2 - 9 }
\end{tabular}} & early & 3 & 75.216 & .000 & .849 & .068 & .835 & .762 \\
\hline \multirow{2}{*}{$\begin{array}{c}\text { Satisfaction } \\
\text { of learning }\end{array}$} & final & 2 & 21.521 & .314 & .972 & .037 & .992 & .976 \\
\cline { 2 - 9 } & final & 4 & 1.094 & .658 & .981 & .004 & .973 & .997 \\
\hline
\end{tabular}

Form of using cyber education was analyzed with number of logging in, learning time, number of using bulletin boards, participation of discussion and learning, and the learning experiences. For verification, we conducted multiplex regression analysis using the learning time and experiences as dependent variables.

The impact that technology factors have on learning time was verified that it has an actual impact with the value of $\mathrm{t}$ as -3.243 , and it is found that general satisfaction about using also have an impact. That is, technology factors and satisfaction for using has affected learning time to a certain extent. The regression model indicates a value of 11.673 at $\mathrm{p}=.000$ of $\mathrm{F}$ value, and when we conducted Durbin-Watson test, it says that the regression model is appropriate because there was not any correlation among values with number 1.501. As a result of verification of affecting relationship between technology factors and learning experiences, t-value was 4.243 , meaning that there is a relationship between them, but contents of learning, interaction, and satisfaction for using seemed not to affect the experiences.

To review whether sex, grade, college which are user attribute has any significant influence on the satisfaction index of each component in category, we conducted ANOVA to compare average between groups and verify it. As the result of ANOVA verification, user satisfaction index according to all components of category, contents of learning $(\mathrm{F}=13.40, \mathrm{p}=.610)$, technology factors $(\mathrm{F}=8.71$, $\mathrm{p}=.070)$, interaction $(\mathrm{F}=1.267, \mathrm{p}=.361)$ turned out to be insignificant within significance level $\mathrm{p} \leq .05$.

As the result of ANOVA verification of user satisfaction index of each component of category according to grade, contents of learning $(\mathrm{F}=11.159$, $\mathrm{p}=.000)$, technology factors $(\mathrm{F}=6.740, \quad \mathrm{p}=.000)$, interaction $(\mathrm{F}=4.840, \quad \mathrm{p}=0.00) \quad$ showed significant difference within significance level $\mathrm{p} \leq .001$.

As the result of ANOVA verification of user satisfaction index of each component of category according to college, contents of learning $(\mathrm{F}=2.148$, $\mathrm{p}=.003)$ technology factors $(\mathrm{F}=6.842, \quad \mathrm{p}=.082)$, interaction $(\mathrm{F}=4.39, \mathrm{p}=.027)$ showed insignificant within significance level $\mathrm{p} \leq .001$.

\section{CONCLUSION}

In this thesis, we analyzed impacts of learning contents, technology factors, and interaction on learners' satisfaction, targeting learners of cyber education. To measure the satisfaction, We organized three category components(Contents, technology factors, interaction), seven classified levels(utility, properness, credibility, diversity, relation, structure, and whether it is easy to be understood), four components of technology factors(convenience for use and approach, speed of responding, outer design), and three components of interaction(interaction, promptness, identification 
services).

Among the variables we used to measure, two things that influence satisfaction of learners: technological variable and general satisfaction about using. In addition, we could figure out that satisfaction of learners affects technological factors and loyalty of learners. There were easiness, interaction and identification service, factors affect on satisfaction and loyalty of learners, and especially the identification service were showed as the biggest variable that would improve both, satisfaction and loyalty.

We can tell that using the results of this research case would be helpful to work on reformation plan of cyber education at colleges. However, because the research had not been conducted with benchmarking and equivalent comparison of other institutions which provide cyber education, so a sample of the same group we used cannot be analyzed, if targeting other cyber education systems. In later, it seems that this limitation of learners' satisfaction index could be supplemented by measurement of PLS.

\section{REFERENCES}

[1] J. G. Proakis and M. Salehi, Digital Communications. 5 th ed. New York: McGraw-Hill, pp. 123-135, 1993.

[2] NCSI, http://www.ncsi.or.kr/

[3] Y. J. Park, S. H. Lee and S. j. Kwak, "System Improvement Strategy by User Satisfaction Index Model Development and Measurement of Information System," KOSIM Journal, vol. 24, no. 4, pp. 173-189, December. 2007.

[4] S. J. Park, H. C. Kim, "Customer satisfaction index and corporation result" Marketing research, Vol.18, NO.3, p19-50, 2003

[5] H. S. Kim, Y. J. Park, "Development and Measurement of user Satisfaction Index Model for Information System," KOSIM Journal, vol. 21, no. 4, pp. 153-171, December. 2004.

[6] J. Y. Hwang, E. B. Lee and H. N. Choi, "An Analysis on Measurement of Customer Satisfaction Index of NDSL," Journal of Korean Library and Information Science Society, vol. 37, no. 4, pp. 247-270, December. 2006.

[7] Chiou, J. S., "The Antecedents of Consumers' Loyalty toward Internet Service Providers," Information \& Management, vol.41, no.6, pp. 685-695, 2004

[8] Fornell, C, "A National Cutomer Satisfaction Barometer: The Swedish Experience," Journal of Marketing, vol. 56, pp. 6-21, 1992.

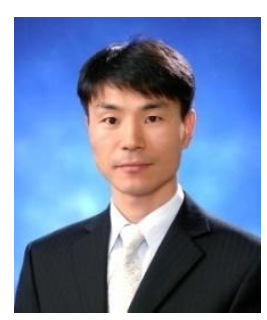

Chang-Su Kim

He received the B.S., M.S. and Ph. D. degrees in Computer Engineering from Paichai University, in 1996, 1998 and 2002, respectively. From 2001 to 2004, he has a lecturer of Paichai University, IT Education Center. Since 2005, he has worked as a Fulltime lecture in Department of Internet at Chungwoon University. His current research interests include Document Information Processing, Web Service, and Mobile Internet Service

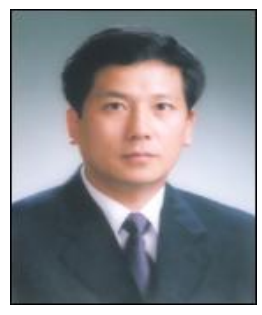

Hoe-Kyung Jung

He received the B.S., M. S. and Ph.D. degrees in computer engineering from Kwangwoon University, in 1985, 1987 and 1993, respectively. Since 1994, he has worked as a professor in Department of Computer Engineering at PaiChai University. His current research interests include XML, semantic web, MPEG-21, Mobile RFID 